\title{
Effects of mental health interventions for students in higher education are sustainable over time: a systematic review and meta-analysis of randomized controlled trials
}

\author{
Regina Winzer Corresp., 1,2 , Lene Lindberg ${ }^{3,4}$, Karin Guldbrandsson ${ }^{1,2}$, Anna Sidorchuk ${ }^{1,5}$ \\ 1 Department of Public Health Sciences, Karolinska Institute, Stockholm, Sweden \\ 2 Department of Living Conditions and Lifestyles, The Public Health Agency of Sweden, Solna, Sweden \\ 3 Department of Public Health Sciences, Karolinska Institute, Solna, Sweden \\ 4 Center for Epidemiology and Community Medicine, Stockholm County Council, Stockholm, Sweden \\ 5 Department of Clinical Neuroscience, Centre for Psychiatry Research, Karolinska Institute, Stockholm, Sweden \\ Corresponding Author: Regina Winzer \\ Email address: regina.winzer@folkhalsomyndigheten.se
}

Background. Symptoms of depression, anxiety, and distress are more common in undergraduates compared to age-matched peers. Mental ill health among students is associated with impaired academic achievement, worse occupational preparedness, and lower future occupational performance. Research on mental health promoting and mental ill health preventing interventions has shown promising short-term effects, though the sustainability of intervention benefits deserve closer attention. We aimed to identify, appraise and summarize existing data from RCTs reporting on whether the effects of mental health promoting and mental ill health preventing interventions sustained at least 3 months post-intervention, and to analyse how the effects vary for different outcomes in relation to follow-up length. Further, we aimed to assess whether the effect sustainability varied by intervention type, study-level determinants and of participant characteristics.

Material and methods. A systematic search in MEDLINE, PsycInfo, ERIC and Scopus was performed for RCTs published in 1995-2015 and reporting an assessment of mental ill health and positive mental health outcomes for, at least, 3 months of post-intervention follow-up. Random-effect modeling was utilized for quantitative synthesis of the existing evidence with standardized mean difference (Hedges' $g$ ) used to estimate an aggregated effect size. Sustainability of the effects of interventions was analysed separately for 3-6 months, 7-12 months and 13-18 months of post-intervention follow-up. Results. 26 studies were eligible after reviewing 6571 citations. The pooled effects were mainly small, but significant for several categories of outcomes. Thus, for the combined mental ill health outcomes, symptom reduction sustained up to 7-12 months post-intervention [standardized mean difference (Hedges' $g$ ) effect size $(E S)=-0.28(95 \% \mathrm{Cl} ;-0.49,-0.08)$ ]. Further, sustainability of symptom-reductions were evident for depression with 
intervention effect lasting up to $13-18$ months [ES $=-0.30(95 \% \mathrm{Cl} ;-0.51,-0.08)]$, for anxiety up to $7-12$ months [ES=-0.27 $(95 \% \mathrm{Cl} ;-0.54,-0.01)$ ], and for stress up to $3-6$ months [ES= $0.30(95 \% \mathrm{Cl} ;-0.58,-0.03)]$. The effects of interventions to enhance positive mental health sustained up to 3-6 months for the combined positive mental health outcomes [ES $=0.32$ $(95 \% \mathrm{Cl} ; 0.05,0.59)]$. For enhanced active coping, sustainability up to $3-6$ months was observed with a medium and significant effect [ES=0.75 $(95 \% \mathrm{Cl} ; 0.19,1.30)]$.

Discussion. The evidence suggests long-term effect sustainability for mental ill health preventive interventions, specially, for interventions to reduce the symptoms of depression and symptoms of anxiety. Interventions to promote positive mental health offer promising, but shorter-lasting effects. Future research should focus on mental health organizational interventions to examine their potential for students in tertiary education. 
1 Effects of mental health interventions for students in higher education

2 are sustainable over time: A systematic review and meta-analysis of

3 randomized controlled trials

4 Regina Winzer ${ }^{1,2}$, Lene Lindberg ${ }^{1,3}$, Karin Guldbrandsson ${ }^{1,2}$, Anna Sidorchuk ${ }^{14}$

5

61 Department of Public Health Sciences, Karolinska Institutet, Stockholm, Sweden

72 Department of Living Conditions and Lifestyles, The Public Health Agency of Sweden, Solna, Sweden

83 Center for Epidemiology and Community Medicine Stockholm County Council, Stockholm, Sweden

94 Centre for Psychiatry Research, Department of Clinical Neuroscience, Karolinska Institutet, Stockholm,

10 Sweden

11

12

13

Corresponding Author:

14

Regina Winzer ${ }^{1,2}$

15

regina.winzer@folkhalsomyndigheten.se

16

17

18 


\section{Abstract}

\section{Background}

22 Symptoms of depression, anxiety, and distress are more common in undergraduates compared to

23 age-matched peers. Mental ill health among students is associated with impaired academic

24 achievement, worse occupational preparedness, and lower future occupational performance.

25 Research on mental health promoting and mental ill health preventing interventions has shown

26 promising short-term effects, though the sustainability of intervention benefits deserve closer

27 attention. We aimed to identify, appraise and summarize existing data from RCTs reporting on

28 whether the effects of mental health promoting and mental ill health preventing interventions

29 sustained at least 3 months post-intervention, and to analyse how the effects vary for different

30 outcomes in relation to follow-up length. Further, we aimed to assess whether the effect

31 sustainability varied by intervention type, study-level determinants and of participant

32 characteristics.

\section{Material and methods}

35 A systematic search in MEDLINE, PsycInfo, ERIC and Scopus was performed for RCTs

36 published in 1995-2015 and reporting an assessment of mental ill health and positive mental

37 health outcomes for, at least, 3 months of post-intervention follow-up. Random-effect modeling

38 was utilized for quantitative synthesis of the existing evidence with standardized mean difference 
39 (Hedges' $g$ ) used to estimate an aggregated effect size. Sustainability of the effects of

40 interventions was analysed separately for 3-6 months, 7-12 months and 13-18 months of post-

41 intervention follow-up.

\section{Results}

4426 studies were eligible after reviewing 6571 citations. The pooled effects were mainly small,

45 but significant for several categories of outcomes. Thus, for the combined mental ill health

46 outcomes, symptom reduction sustained up to 7-12 months post-intervention [standardized mean

47 difference (Hedges' $g$ ) effect size $(E S)=-0.28(95 \% \mathrm{CI} ;-0.49,-0.08)]$. Further, sustainability of

48 symptom-reductions were evident for depression with intervention effect lasting up to 13-18

49 months $[\mathrm{ES}=-0.30(95 \% \mathrm{CI} ;-0.51,-0.08)]$, for anxiety up to $7-12$ months $[\mathrm{ES}=-0.27(95 \% \mathrm{CI}$; -

$500.54,-0.01)]$, and for stress up to $3-6$ months $[\mathrm{ES}=-0.30(95 \% \mathrm{CI} ;-0.58,-0.03)]$. The effects of

51 interventions to enhance positive mental health sustained up to 3-6 months for the combined

52 positive mental health outcomes [ES=0.32 (95\%CI; 0.05, 0.59)]. For enhanced active coping,

53 sustainability up to 3-6 months was observed with a medium and significant effect $[\mathrm{ES}=0.75$

$54(95 \% \mathrm{CI} ; 0.19,1.30)]$.

\section{Discussion}

57 The evidence suggests long-term effect sustainability for mental ill health preventive

58 interventions, specially, for interventions to reduce the symptoms of depression and symptoms of anxiety. Interventions to promote positive mental health offer promising, but shorter-lasting 
60 effects. Future research should focus on mental health organizational interventions to examine

61 their potential for students in tertiary education.

64 INTRODUCTION

Mental health problems among students in higher education is an emerging public health issue and evidence-based prevention is essential (Christensson et al. 2010; Dahlin et al. 2011; Garlow et al. 2008; Hunt \& Eisenberg 2010; Steptoe et al. 2007). Recent systematic reviews on student health raise concerns over high rates of mental ill health outcomes with pooled prevalence ranging between $27 \%$ and $34 \%$ for depression and depressive symptoms and reaching $11 \%$ for suicidal ideation (Ibrahim et al. 2013; Rotenstein et al. 2016; Tung et al. 2018). Also, a two-fold risk for suicide is shown during ongoing university studies compared to when having attained university studies (Lageborn et al. 2017). Elevated rates of mental ill health, namely symptoms of distress, anxiety and depression, in undergraduates appear to substantially exceed the corresponding estimates in age-matched peers (Cvetkovski et al. 2012; Dyrbye et al. 2006; Leahy et al. 2010; Winzer et al. 2014) and the general population (Ibrahim et al. 2013; Rotenstein et al. 2016). Female students, minority groups and students with financial problems constitute groups with higher risks (Cvetkovski et al. 2012; Eisenberg et al. 2013; Said et al. 2013). Once heightened at the beginning of the study period, the symptoms of anxiety and depression remain elevated over the academic years and at no time point drop down to preregistration levels (Bewick et al. 2010). Mental ill health among students may potentially be 
81 caused by heavy workload, insufficient feedback from teachers and worries about future

82

83

84

85

86

87

88

89

90

91

92

93

94

95

96

97

98

endurance/competence (Dahlin et al. 2005), but may also reflect the increase in deteriorated mental health among adolescents (Hunt \& Eisenberg 2010). Mental ill health problems are often accompanied by decrements in positive mental health through lowered self-perception, inadequate social-emotional skills and poor interpersonal relationships (Conley et al. 2015).

Moreover, perceived academic stress and burn-out are associated with impaired academic achievement (Andrews 2004; Keyes et al. 2012; Vaez \& Laflamme 2008), worse occupational preparedness and lower occupational performance after the graduation (Rudman \& Gustavsson 2012). In prevention science the health promotion approach constitutes a substantial ingredient of the integrative model for mental health intervention in youth (Weisz et al. 2005). Including aspects of positive mental health, i.e. emotional, psychological and social well-being (Westerhof \& Keyes 2010) is a beneficial strategy in mental health interventions (Kobau et al. 2011). It has been shown that psychological assets, e.g. boostering positive emotions, coping strategies and compassion may help people to manage life's challenges. Thus, promoting mental health and preventing mental ill health are two essential and complementary steps in reducing the burden of disease (Jane-Llopis 2007; Keyes 2007; World Health Organization (WHO) 2002).

Previous research on mental health promotion and mental ill health prevention has shown promising short-term effects of stress reduction techniques and meditation, self-hypnosis, cognitive behavioural and mindfulness interventions (Conley et al. 2015; Conley et al. 2017; Regehr et al. 2013; Shiralkar et al. 2013) as well as of technology based interventions (Conley et al. 2016; Davies et al. 2014; Farrer et al. 2013). As mental health problems persist during the study period (Bewick et al. 2010; Christensson et al. 2010) and negatively affect academic performance and future working capacity (Rudman \& Gustavsson 2012; Vaez \& Laflamme 
104 2008), the sustainability of intervention benefits as well as its determinants and moderators

105 deserve closer attention. Several reviews have approached the issue of intervention effect

106 sustainability by averaging the effects reported for the longest follow-up periods, although a

107 substantial variability in the ranges and means of the follow-up lengths made the comparions

108 difficult (Conley et al. 2015; Conley et al. 2016; Conley et al. 2017). The authors highlighted the

109 need for in-depth investigation of the intervention benefit sustainability over variable

110 postintervention follow-up periods since the effects may change their direction and strength over

111 time (Conley at al. 2015). Therefore, to further address the nature of sustainability of

112 intervention effects, in this review we aimed to systematically identify, appraise and summarize

113 the existing data from randomized control trials (RCT) reporting on whether the effects of mental

114 health promoting and mental ill health preventing interventions are sustained for at least 3

115 months of post-interventional follow-up. Further, we aimed to analyse how the direction and

116 magnitude of the effects vary for different outcomes in relation to the lengths of follow-up and to

117 assess whether effect sustainability varied by the types and major features of interventions,

118 study-level determinants, and characteristics of participants.

\section{Eligibility criteria}

122 The protocol was registered in PROSPERO, CRD42015029353 (Data, S1). The study followed

123 the guidelines for conducting systematic review as suggested by the Cochrane handbook for

124 systematic reviews of interventions (Higgins et al. 2008) and reported the study findings and

125 procedure in relation to the sec statement (Moher et al. 2009) (Table, S5). 
127 developed after discussing eligibility criteria with stakeholders from the student health services:

$128 \mathrm{P}=$ students in university settings; $\mathrm{I}=$ any types of mental health-promoting and mental ill health-

129 preventing interventions; $\mathrm{C}=$ any types of active or inactive controls; $\mathrm{O}=$ (i) positive mental

130 health, including well-being, coping, locus of control, resilience, self-esteem/self-compassion,

131 stress management, academic achievement or academic performance, and (ii) mental ill health,

132 including symptoms of anxiety, symptoms of depression, psychological distress, worry, fatigue,

133 sleeping problems, and perceived stress. The study design was restricted to RCTs with at least 3

134 months of post-intervention follow-up. No language restrictions were initially applied. Studies

135 focused on students with diagnosed psychiatric disorders and studies conducted in primary care

136 settings were excluded.

137

138 Search strategy

139 In collaboration with librarians (CG, AW: see Acknowledgements), a sensitive search strategy

140 was developed and adapted to the following databases: Medline (Ovid), PsycInfo (Ovid), Eric

141 (Ovid) and Scopus. Gray literature was searched in Dissertations \& Theses (ProQuest), Dart

142 Europe, OpenGrey and Base Bielefeld. The searches were limited to studies published from

143 January 1, 1995 to December 31, 2015. Key words and MESH terms are reported in the

144 Supplemental Information (Data, S2 and Data, S3, respectively). Reference lists of the relevant

145 reviews and studies selected for inclusion were manually scrutinized and the following journals

146 were hand-searched from January 2012 to March 2016: College Student Journal, Journal of

147 American College Health and Journal of College Counseling. 
149 Study selection, data extraction and quality assessment

150 Screening was conducted independently by two authors (RW, KG) and two colleagues (AF, AM:

151 see Acknowledgement). The eligibility of each article was initially evaluated by the title and

152 abstract and, if found appropriate, followed by full-text examination. At this stage only English-

153 language publications were assessed. This resulted in a loss of 20 publications in Chinese

$154(\mathrm{k}=15)$, Japanese $(\mathrm{k}=3)$, Korean $(\mathrm{k}=1)$ and Spanish $(\mathrm{k}=1)$. Gray literature was taken into

155 consideration when accessible free of charge. Any disagreements were resolved through panel

156 discussions. Studies selected for inclusion were examined for potential overlap in study

157 populations, which was not found.

Data extracted from the articles included first author, country of origin, setting,

159

160

161

162

163

164

165

166

167

168

169

170 funding, inclusion and exclusion criteria, characteristics of the intervention and comparison groups (age, gender, ethnicity), characteristics of the intervention (type, format, delivery level, length of session, duration), type of comparison, outcome definition and measurement scale, sample size, post-intervention length of follow-up, percent of withdrawals at each measurement point and study quality (described below). If a study reported multiple outcomes and/or if outcomes were assessed at multiple follow-up time points, quantitative data (means and standard deviations (SD)) were extracted separately for each outcome at each follow-up period. The same approach was utilized for multi-armed RTCs, from which separate extraction was performed for each intervention-comparison pair. When data were missing in the original reports we contacted authors for further clarification.

As suggested by Conley, et al. (Conley et al. 2015), original interventions were grouped into: (i) cognitive behaviour therapy (CBT)-related if focusing on identifying and 
171 changing unhelpful cognitions, behaviors and emotional regulation; (ii) mind-body-related, i.e.,

172 interventions that facilitate the mind's capacity to affect bodily function and symptoms; and (iii)

173 psycho-educational-related if focusing on information, discussion and didactic communication

174 on, e.g. stress-reduction and coping. Categorization was based on the original definitions, if

175 provided, and otherwise by us. Level of delivery was considered as universal if intervention

176 targeted students without reported mental ill health symptoms and as selective if provided for

177 those with adverse mental health symptoms. Interventions were further divided into group or

178 individual format. Comparators were sub-divided into active controls (i.e., another type of

179 intervention) and inactive controls (waitlist controls, placebo-controls, "living as usual" and no

180 intervention). Study outcomes were classified in two major categories: mental ill health

181 outcomes consisting of anxiety symptoms, depressive symptoms, psychological distress, stress,

182 self-reported worry, passive coping, and deteriorated quality of sleep; and positive mental health

183 and academic performance outcomes including self-esteem, self-compassion, self-efficacy,

184 mental or subjective well-being, resilience, active coping, happiness, stress management and

185 academic performance.

186

187

188

189

190

191

192

193
The quality of selected trials was assessed independently by three authors (RW,

KG, LL) and colleagues (AF, AM, SB: see Acknowledgements) using the Effective Public

Health Practice Project Quality Assessment Tool (EPHPP), as recommended by the Cochrane

Collaboration for public health reviews (Higgins et al. 2008). The EPHPP assesses selection bias, study-design, confounders, blinding, data collection method and withdrawals and dropouts to yield the study quality as either strong, moderate or weak. Discrepancies in quality assessment were resolved by discussions with one of the three reviewers not involved in the review process. 


\section{Statistical analysis}

195 Because of the variety of instruments used for measuring outcomes, a standardized mean

196 difference using Hedges' $g$ was chosen as a common effect size (ES) for conducting quantitative

197 synthesis. ES was calculated separately at each post-intervention follow-up time point as a

198 difference in means between intervention and control group, divided by the pooled within-group

199 SD and incorporating a correction factor for small sample sizes (Borenstein et al. 2009). One

200 trial reported Hedges' $g$ as the study ES (Braithwaite \& Fincham 2009), while for other studies it

201 was calculated from the available raw data. Throughout the recalculations we kept the original

202 direction of scales indicating the improvement of outcome measures. Thus, for mental ill health

203 outcomes ESs below zero pointed to superiority of the intervention group over the controls,

204 while for positive mental health and academic performance outcomes, ESs above zero indicated

205 that the results favored the intervention. For one study where follow-up means, but not SDs,

206 were provided and the intervention effect was indicated as "non-significant" (Chiauzzi et al.

207 2008), we set ES to zero. To ease interpretation of the magnitude of Hedges' $g$, we applied

208 Cohen's convention (Cohen 1992) and defined the ES as small (0.2), medium (0.5), and large

$209(0.8)$.

Precautions were taken to overcome unit-of-analysis error and avoid using multiple

211

212

213

214

215

216

assessment of the same construct (Higgins et al. 2008). If more than one ES was reported in a given study for the same outcome at a given follow-up point (e.g., for depression assessed by both the Hamilton Depression Rating Scale and Beck Depression Inventory), we averaged ESs to obtain the single outcome measure per intervention at each measurement point (Higgins 2006; Jones \& Johnston 2000; Kanji et al. 2006; Peden et al. 2001; Seligman et al. 1999). ESs were also averaged within the trials with multiple interventions of similar nature, i.e. if interventions 
217 belonged to the same category (Chiauzzi et al. 2008; Mak et al. 2015). A similar approach was

218 applied to studies with multiple comparisons (Chiauzzi et al. 2008; Rohde et al. 2014; Yang et al.

219 2014). An exception was the study by Kanji N et al. (Kanji et al. 2006), where two control

220 groups - an attention control and a time control - were included separately as considered to be

221 different in approach and content and, thus, representing active and inactive comparisons,

222 respectively.

Meta-analysis was conducted for all specific outcomes originally reported and for

224 outcomes combined within mental ill health and positive mental health and academic

225 performance categories. To analyze the combined outcomes, we applied a hierarchical approach

226 for selecting outcomes from the studies reporting more than one from the same category. The

227 hierarchy was based on descending order of outcome reporting, i.e. from the most often reported

228 to the least often reported. For mental ill health outcomes the hierarchical selection was ordered

229 as: depressive symptoms, anxiety symptoms, stress, psychological distress, self-reported worry,

230 quality of sleep and passive coping. For positive mental health and academic performance

231 outcomes the order was: self-esteem, academic performance, self-efficacy, self-compassion,

232 mental or subjective well-being, resilience, stress management, active coping, and happiness.

Because of the initial assumptions of between-study heterogeneity, a random-

effects model incorporating both within- and between-study variability was used for quantitative synthesis. To assess the sustainability of intervention effect over time and address the variety of the follow-up lengths reported in the original studies, we categorized the post-intervention

237 follow-ups as 3-6 months, 7-12 months, and 13-18 months. Each of the included studies reported

238 outcome measures for at least one of these categories and quantitative synthesis was conducted separately for each category. If a given study provided several outcome measures falling in the 
240 same length category (e.g., for both 3 and 6 month follow-ups), the ES for the follow-up close to

241 the upper boundary (i.e., 6 months) was chosen (Kanji et al. 2006; Seligman et al. 2007; Vazquez

242 et al. 2012). Only one study (Seligman et al. 1999) assessed outcomes at follow-up periods

243 longer than 18 months and the measurements of those periods (i.e., 24 months, 30 months and 36

244 months) were not included in the meta-analysis. Finally, to obtain comparability between trials,

245 if a study provided results based on both imputed data (i.e., intention-to-treat analysis) and non-

246 imputed data (i.e., follow-up completers) (Reavley et al. 2014) or if both crude and adjusted ESs

247 were available (Chase et al. 2013) we favored the imputed and crude measures for the main

248 analysis leaving the latter (non-imputed and adjusted measures) for sensitivity analysis.

We evaluated statistical heterogeneity among the studies using $Q$ and $I^{2}$ statistics.

250

251

252

253

254

255

256

257

258

259

260

261

262

For $Q$, p-value $<0.1$ was considered as representative of statistically significant heterogeneity, and $I^{2}$ values of $25 \%, 50 \%$ and $75 \%$ were indicating low, moderate and high heterogeneity, respectively (Higgins et al. 2003).

The subgroup analyses were performed by stratifying the main analysis by a priori identified moderators related to interventions (category of intervention, delivery level, type of format, type of controls), study-level moderators (initial study size, study quality) and moderators related to participant characteristics (gender, country). The analyses were performed if at least two studies were included in each subgroup. Mixed-methodology was applied with random-effect modeling used for within-group pooling, while between-group differences were assessed with fixed-effect model. Leave-one-out influence analysis was conducted to assess the potential impact of individual studies on the overall pooled ES by omitting one study at a time (Tobias 1999). Following the approach suggested by Hart et al (Hart et al. 2012), sensitivity analysis was conducted to assess whether the overall pooled ES differed if the lowest or the 
263 highest original ES was selected from the studies with multiple outcome assessments or multiple

264 interventions or comparisons. In meta-analyses with three or more studies included, we assessed

265 publication bias by funnel plots, Egger's regression asymmetry test, and the Begg-Mazumdar

266 adjusted rank correlation test (Begg \& Mazumdar 1994; Egger et al. 1997).

All statistical analyses were performed using STATA version 13.1 (StataCorp,

268 College Station, TX). P-values $<0.05$ were considered statistically significant. All statistical

269 tests were two-sided.

270

$271 \quad$ RESULTS

272 After removing the duplicates, 6571 records were available for title and abstract screening.

273 Among these, 6519 records were excluded as not meeting the PICO-criteria, leaving 52 articles

274 for full-text examination. Further evaluation excluded another 26 studies: post-intervention

275 follow-up less than 3 months $(\mathrm{k}=11)$, not enough data to calculate ES $(\mathrm{k}=6)$, not a $\mathrm{RCT}(\mathrm{k}=5)$,

276 population not relevant $(\mathrm{k}=3)$, and outcome not relevant $(\mathrm{k}=1)$. A selection process yielded a

277 final number of 26 RCTs to be included in the meta-analysis (Fig. 1).

278

279 Figure 1 Flow diagram of the study selection process.

280

281 Characteristics of included studies 
282 Table 1 summarizes the characteristics of studies eligible for inclusion. Among the $26 \mathrm{RCTs}$

283 (Braithwaite \& Fincham 2009; Chase et al. 2013; Cheng et al. 2015; Chiauzzi et al. 2008; Erogul

284 et al. 2014; Fontana et al. 1999; Franklin \& Franklin 2012; Gortner et al. 2006; Hamdan-

285 Mansour et al. 2009; Higgins 2006; Jones \& Johnston 2000; Kanji et al. 2006; Kattelmann et al.

286 2014; Kenardy et al. 2006; Li et al. 2015; Mak et al. 2015; Pachankis \& Goldfried 2010; Peden

287 et al. 2001; Reavley et al. 2014; Rohde et al. 2014; Seligman et al. 1999; Seligman et al. 2007;

288 Shapiro et al. 2011; Vazquez et al. 2012; Yang et al. 2014; Zheng et al. 2015), CBT-related

289 interventions were assessed in 11 studies, while mind-body-related and psycho-educational-

290 related interventions were assessed in 10 and 5 studies, respectively. Universal and selective

291 delivery levels were equally present ( $\mathrm{k}=13$ for both). Face-to-face group format was the most

292 common $(\mathrm{k}=16)$. At least one mental ill health outcome was assessed in 24 studies, while at least

293 one positive mental health outcome was appraised in 14 studies. Twenty-three trials reported at

294 least one outcome measurement during 3-6 months post-intervention follow-up, with 8 and 5

295 trials reporting corresponding measurements during 7-12 months and 13-18 months follow-ups.

296 None of the interventions had an organizational approach. More detailed characteristics of the

297 selected studies are presented on-line (Table S1). The study quality assessed in all 26 RCTs

298 varied between strong $(\mathrm{k}=4)$, moderate $(\mathrm{k}=12)$ and week $(\mathrm{k}=10)$. When subdivided by the

299 outcome categories, 24 trials with at least one mental ill health outcome revealed their study

300 quality as strong $(\mathrm{k}=4)$, moderate $(\mathrm{k}=11)$ and weak $(\mathrm{k}=9)$, and 14 trials with at least one positive

301 mental health outcome and academic performance of strong $(\mathrm{k}=3)$, moderate $(\mathrm{k}=6)$ and weak

$302(n=5)$ quality. Across all studies included in the analysis, selection bias was the most commonly

303 assessed weakness component $(\mathrm{n}=21)$. (Table S2). 
305

306

307

308

309

310

311

312

313

314

315

316

317

318

319

320

321

322

323

324

325

326

Table 1 Summary of descriptive characteristics of randomized controlled trials included in the systematic review and meta-analysis.

\section{Effects and sustainability over time}

\section{Interventions preventing mental ill health}

As presented in Table 2, for the combined mental ill health outcomes an aggregated ES for all preventive interventions yielded a superiority of interventions over the comparisons at 3-6 months and 7-12 months of post-intervention follow-up, although the effects were small. Pooled ES did not reach statistical significance for follow-up periods of 13-18 months. High-tomoderate heterogeneity was detected at all three follow-up periods with $I^{2}$ of $79.5 \%, 74.2 \%$, and $58.2 \%$, respectively. Publication bias was evident for studies with 3-6 months follow-up (Egger's test $\mathrm{p}$-value $=0.013)$, though not for studies with longer follow-up periods (7-12 months: $\mathrm{p}$ value $=0.151 ; 13-18$ months: $p$-value $=0.141)$, (Figure, S1). Influence analysis revealed no indication that individual RCTs, if omitted, would significantly influence the observed overall ESs (data not shown). As previously noted, sensitivity analyses were performed for studies with multiple outcome measures reported for the same follow-up and for studies with multiple interventions or comparisons. Pooling together the highest ESs originally reported for these studies did not alter the results of the main analysis 3-6 months: $\mathrm{ES}=-0.28(95 \% \mathrm{CI}-0.44$, 0.12); 7-12 months: $\mathrm{ES}=-0.35(95 \% \mathrm{CI}-0.60,-0.10) ; 13-18$ months: $\mathrm{ES}=-0.23$ (95\% CI -0.54 , 0.08)). Neither were the results influenced when the lowest originally reported ESs were used (36 months: $\mathrm{ES}=-0.24(95 \% \mathrm{CI}-0.39,-0.09)$; $7-12$ months: $\mathrm{ES}=-0.23(95 \% \mathrm{CI}-0.43,-0.03) ; 13-$ 18 months: $\mathrm{ES}=-0.06(95 \% \mathrm{CI}-0.18,0.06))$. Only one study reported the results using both 
327 imputed and non-imputed data (Reavley et al. 2014), with the former included in the main meta-

328 analysis. Alternative inclusion of the latter did not change the overall ES (data not shown).

In sub-group analyses for the combined mental ill health outcomes, studies employing CBT-related interventions revealed singificant pooled ESs for 3-6 month and 13-18 month follow-ups (Table 2 and Figure 2). Less consistent results were observed for mind-bodyrelated interventions. No superiority of intervention group appeared among studies with psychoeducational interventions. Pooled ESs for universal preventive interventions yielded significant results for follow-up up to 7-12 months. Less consistency appeared in the aggregated results for selective interventions and interventions conducted face-to-face in groups. Trials with small sample size and trials comprising more than $60 \%$ females yielded significant effects for up to 7 12 months of follow-up. The small numbers of studies might explain the lack of consistency in the results of other sub-group comparisons. The high heterogeneity seen for studies with 3-6 months of follow-up might reflect differences in delivery level ( $\mathrm{p}$-value for $\mathrm{Q}$ between subgroups $=0.006)$ and study size $(\mathrm{p}<0.001)$, while for studies with follow-up periods of 7-12 months, heterogeneity could be explained by differences in type of comparison $(\mathrm{p}<0.001)$, study size $(p=0.01)$, and country where the RCT was conducted $(p=0.003)$. We were unable to detect between-group differences for trials with follow-up of 13-18 months because of the small number of studies in the sub-groups.

Assessment of the specific mental ill health outcomes, revealed a sustainable effect

$347(95 \%$ CI $-0.51,-0.08))$, (Table, S3). For symptoms of anxiety sustainability was observed up to 348 7-12 months (ES=-0.27 (95\%CI; -0.54, -0.01)). Only one study assessed the effect of interventions targeting anxiety during 13-18 months of post-intervention follow-up and, hence, 
350 we were unable to perform meta-analysis. For symptoms of stress, reductions lasted up to 3-6

351 months post intervention $(\mathrm{ES}=-0.30(95 \% \mathrm{CI} ;-0.58,-0.03))$. Other comparisons were either

352 inconclusive or quantitative synthesis was not performed because of the small number of studies.

354 Table 2 Meta-analysis and sub-group analyses for hierarchically selected mental ill health 355 outcomes, stratified by the length of post interventional follow-up periods.

356 Figure 2 The effects of mental ill health preventing interventions on hierarchically selected mental ill health outcomes stratified by the length of post interventional follow-up periods.

Interventions promoting mental health and academic performance - a paucity of outcomes

Table 3 presents overall ESs for the combined positive mental health and academic performance outcomes with rather limited data available, in particular, for the follow-up periods longer than 3-6 months. All interventions combined showed superiority over the controls during 3-6 months of follow-up with small, but significant pooled ES. For longer follow-up periods the results were inclonclusive. High heterogeneity was detected when studies with 3-6 months follow-up were pooled $\left(I^{2}=86.5 \%\right)$. Because of the small number of studies, publication bias were only assessed

367 for studies with 3-6 months of follow-up and were detected (Egger's test p-value=0.03) (Figure, 368 S5). Influence analysis indicated that four individual studies (Erogul et al. 2014; HamdanMansour et al. 2009; Pachankis \& Goldfried 2010; Peden et al. 2001), if omitted, would drop the

370 significant overall ES for the studies with 3-6 months follow-up to borderline significance (data 
371 not shown). Overall ESs at follow-ups of 7-12 and 13-18 months remain non-significant

372 regardless of individual study influences (data not shown). Sensitivity analyses pooling the

373 highest ESs originally reported for studies with multiple outcome assessment or multiple

374 interventions or comparison groups showed no alteration to the overall results at 3-6 months

375 follow-up $(\mathrm{ES}=0.32(95 \%$ CI $0.06,0.58))$, but made the overall ESs for 7-12 months follow-ups

376 significant $(\mathrm{ES}=0.53(95 \% \mathrm{CI} 0.20,0.87))$, as well as for $13-18$ months follow-up $(\mathrm{ES}=0.53$

377 (95\% CI $0.21,0.86))$. However, only 2 studies were assessed within each category of 7-12 and

378 13-18 months follow-ups. Use of the lowest originally reported ES did not affect the results of

379 the main analysis (3-6 months: $\mathrm{ES}=0.32(95 \% \mathrm{CI} 0.06,0.58) ; 7-12$ months: $\mathrm{ES}=0.16(95 \% \mathrm{CI}-$

$3800.18,0.50) ; 13-18$ months: $\mathrm{ES}=0.16(95 \% \mathrm{CI}-0.17,0.49))$. One study reported both crude and

381 adjusted outcome assessment (Chase et al. 2013). Use of the adjusted ES for sensitivity analysis

382 did not alter the results observed in the main analysis.

Sub-group analyses for the combined positive mental health and academic

384

385

386

387

388

389

390

391

392

393

performance outcomes were performed only for studies with 3-6 months follow-up (Table 3 and

Figure 3). Superiority of interventions over comparisons was shown for CBT-related interventions, selective delivery level, face-to-face group format, RCTs with inactive comparisons, studies with small sample size and trials conducted in US. Between-group difference was significant for delivery level $(\mathrm{p}<0.001)$, format type $(\mathrm{p}<0.001)$, study size $(\mathrm{p}<0.001)$ and gender mix $(\mathrm{p}=0.02)$. Sub-group analyses for studies with longer follow-up revealed either non-significant results or were impossible to conduct owing to the small number of trials in the sub-groups.

Because of lack of data on the specific positive mental health and academic performance outcomes, only studies on active coping, self-esteem and self-efficacy with 3-6 
394 months follow-up were quantitatively assessed (Table, S4). Sustainability of the intervention

395 effect was observed for active coping (ES=0.75(95\%CI; 0.19, 1.30)) with no significant effects

396 shown for other outcomes.

397

398

399

Table 3 Meta-analysis and sub-group analyses for hierarchically selected positive mental health

400 and academic performance outcomes stratified by the length of post interventional follow-up

401 periods.

402

403

404

Figure 3 The effects of mental health promoting interventions on hierarchically selected positive mental health and academic performance outcomes stratified by the length of post interventional 405 follow-up periods.

406

407

408

\section{DISCUSSION}

Our systematic review and meta-analysis showed sustainability of the benefits of mental health

410 interventions targeting students in higher education, though in most of the analyses, the pooled

411 ESs yielded significant, but small overall effects. For the combined mental ill health outcomes,

412 the observed effects across all preventive interventions were sustained for up to 7-12 months

413 post-intervention. Sustainability of effects was most pronounced for interventions designed to 
414 reduce the symptoms of depression, for which the superiority of intervention groups over the

415 comparisons remained significant for up to 13-18 months post-intervention. For the combined

416 positive mental health and academic performance outcomes, aggregated results across all

417 promotion interventions revealed slightly shorter, but still evident sustained effects, which

418 remained significant at post-intervention follow-up of 3-6 months.

To our knowledge, this is the first systematic review and meta-analysis focusing

primarily on the sustainability of the effects of mental health promoting and mental ill health

421 preventing interventions among students in higher education and analyzing different categories

422 of follow-up duration. A direct comparison to the existing literature was therefore difficult as

423 other reviews mostly assessed the effects measured at the completion of interventions. The

424 closest comparisons are three reviews by Conley at al. on universal and indicated mental health

425 prevention programs (Conley et al. 2015; Conley et al. 2017) and technology-delivered

426 preventive interventions (Conley et al. 2016). The reviews by Conley et al. assessed the effects

427 of interventions across all types of adjustment outcomes in university students at the longest

428 follow-up period reported, which varied from 2 to 52 weeks (Conley et al. 2015), 13 to 52 weeks

429 (Conley et al. 2016) and 4 to 157 weeks (Conley et al. 2017). The first review (Conley et al.

430 2015) showed the duration of follow-up to be negatively correlated with aggregated ES across

431 mental ill health and positive mental health outcomes combined as well as no effect for psycho-

432 educational interventions. A similar tendency for the effects of intervention to become non-

433 significant as the duration of follow-up increases was observed in our study, though the

434 sustainability of effects differed between ill-health and positive mental health outcomes. As in

435 Conley's review (Conley et al. 2015), no effects of psycho-educational interventions on any

436 outcomes were evident in our data, regardless of the duration of follow-up. The second review 
437 (Conley et al. 2016) reported a significant effect of universal interventions at any follow-up

438 periods ranging between 13 to 52 weeks as well as a positive effect of selective interventions

439 during the follow-up periods of 2-26 weeks. Similarly, in our study mental ill health outcomes

440 were reduced by universal interventions for up to 7-12 months of follow-up and by selective

441 interventions at follow-ups of up to 3-6 months, although our results on positive mental health

442 and academic performance outcomes were less conclusive. Similar to the third review (Conley et

443 al. 2017), our results indicated that the most sustainable effects were observed for interventions

444 designed to reduce the symptoms of depression and symptoms of anxiety.

Although our literature search for intervention studies was not limited to psychological interventions, only this type was retrieved. The scarcity of organizational mental

447 health promoting interventions was verified by a scoping review (Enns et al. 2016). However, an 448 exception may be a recent systematic review on learning environment interventions for medical 449 student well-being, suggesting changes to curriculum (Wasson et al. 2016). Their results support 450 previous findings suggesting that to maximize the effectiveness of mental health promotion, all

451 levels of delivery must contribute, i.e., not just individual and group levels, but also structural, 452 and societal levels (Hamilton \& Bhatti 1996). To further improve the sustainability of student mental health promotion, psychological interventions may be combined with a whole-setting 454 approach, as endorsed by the WHO initiative Health Promoting Universities (HPU) (World 455 Health Organization 1995).

\section{Limitations}


459 Systematic reviews on student mental health have indicated lack of follow-up data on outcome 460 assessment as a major obstacle for determining the long-term effect of interventions (Conley et 461 al. 2015; Conley et al. 2016; Davies et al. 2014; Farrer et al. 2013). Likewise, the scarcity of 462 studies assessing the effects of interventions at post-interventional follow-ups of longer than 3 463 months along with a substantial variability in the lengths of follow-ups reported in the original 464 studies should be considered as major limitations of our review. In particularly, the lack of 465 original evidence affected our analysis of positive mental health outcomes as it restricted us to mainly aggregating the effects of interventions with 3-6 months of follow-up. Other limitations

467

must also be considered. First, in most cases low numbers of studies in sub-groups prevented us from exploring the moderating effect of types of interventions, study-level determinants and participant characteristics during follow-up periods longer than 6 months making the results of sub-group analyses tentative. This also precluded us from conducting in-depth investigation of sources for heterogeneity, which was found to be mostly high. Second, our intention to analyse two dimentions of mental health, that resulted in combining the original outcomes into the "mental ill health" and "positive mental health and academic performance" outcome categories, with a hierarchical approach applied, could have boosted heterogeneity. In a subsequent analyses, we attempted to reduce heterogeneity by pooling together the studies with the same specific outcomes reported, though for several outcomes it was not possible due to data scarcity. Third, the evidence was insufficient to obtain any aggregated ESs for the specific outcomes, in particular, for self-reported worries, passive coping, academic performance, self-compassion, mental and subjective well-being, resilience and happiness rating. Fourth, a substantial variability exists in measurements instruments and, in several cases, the same outcome was measured by different scales. We tried to address this limitation by choosing Hedges' $g$ as an ES 
482 and by investigating how sensitive the aggregated results were to our initial approach of

483 combining the original ESs in cases of multiple outcome measures or in multi-armed RCTs. The

484 sensitivity analyses proved the robustness of our findings for mental ill health, though for

485 positive mental health outcomes the use of the lowest ESs from the original studies altered the

486 results for studies with 7-12 and 13-18 months of follow-up. Fifth, more than 30\% of the original

487 studies were assessed as being of weak quality. To address this issue, we conducted sub-group

488 analyses stratifying the trials by study quality. For both categories of outcomes, these analyses

489 revealed inconclusive results when trials with insufficient quality were pooled that should be

490 accounted when interpreting our results. Furthermore, selection bias as the most commonly

491 identified weakness. This bias, whether induced by the investigators or caused by self-selection

492 may have resulted in either underestimation or overestimation of the original ES and therefore

493 could affect the aggregated results. Finally, the results should be seen in the context of the

494 presence of publication bias among the studies with 3-6 months of follow-up and of our inability

495 to assess publication bias for positive mental health outcomes at follow-ups longer than 6

496 months, which may have resulted from our restriction to English-language publications at the

497 final stage of selection.

498

499 CONCLUSIONS

500 Despite the limitations, the evidence suggests long-term effect sustainability for mental ill health

501 preventive interventions, in particular, for interventions to reduce the symptoms of depression

502 and symptoms of anxiety. Interventions designed to promote positive mental health offer

503 promising, but shorter-lasting effects. As the research field of health promoting interventions for 
504 students expands, future studies may improve our attempts to establish the effectiveness and

505 sustainability of those interventions, e.g., ascertaining the effects for specific positive mental

506 health outcomes. In addition, future research should also focus on mental health organizational

507 interventions to investigate their potential for students in tertiary education.

508

509 Acknowledgements

510 We gratefully acknowledge Anders Wändahl and Carl Gornitzki, University Library, Karolinska

511 Institutet for advice and support and for providing us with electronic searches; our colleagues,

512 Annika Frykholm, Anna Månsdotter and Sven Bremberg who contributed to the screening and

513 extraction of data-base searches; and stake-holders from Student Health Services for valuable

514 input for practice.

515

\section{References}

Andrews. 2004. The relation of depression and anxiety to life-stress and achievement in students. The British journal of psychology 95:509. 10.1348/0007126042369802

Begg CB, and Mazumdar M. 1994. Operating characteristics of a rank correlation test for publication bias. Biometrics:1088-1101.

Bewick B, Koutsopoulou G, Miles J, Slaa E, and Barkham M. 2010. Changes in undergraduate students' psychological well-being as they progress through university. Studies in Higher Education 35:633-645.

Borenstein M, Hedges LV, Higgins J, and Rothstein HR. 2009. Effect sizes based on means. In: Borenstein $\mathrm{M}$, Hedges L, Higgins J, and Rothstein H, eds. Introduction to Meta-Analysis. Chichester: Wiley, 21-32.

Braithwaite SR, and Fincham FD. 2009. A randomized clinical trial of a computer based preventive intervention: replication and extension of ePREP. Journal of Family Psychology 23:32-38. http://dx.doi.org/10.1037/a0014061

Chase JA, Houmanfar R, Hayes SC, Ward TA, Vilardaga JP, and Follette V. 2013. Values are not just goals: Online ACT-based values training adds to goal setting in improving undergraduate college 
532

533

534

535

536

537

538

539

540

541

542

543

544

545

546

547

548

549

550

551

552

553

554

555

556

557

558

559

560

561

562

563

564

565

566

567

568

569

570

571

572

573

574

575

576

577

578

579

student performance. Journal of Contextual Behavioral Science 2:79-84.

10.1016/j.jcbs.2013.08.002

Cheng M, Hasche L, Huang H, and Su XS. 2015. The effectiveness of a meaning-centered psychoeducational group intervention for Chinese college students. Social Behavior and Personality 43:741-756. http://dx.doi.org/10.2224/sbp.2015.43.5.741

Chiauzzi E, Brevard J, Thurn C, Decembrele S, and Lord S. 2008. "MyStudentBody-Stress: An online stress management intervention for college students" Erratum. Journal of Health Communication 13:827. http://dx.doi.org/10.1080/10810730802619404

Christensson A, Runeson B, Dickman PW, and Vaez M. 2010. Change in depressive symptoms over higher education and professional establishment - a longitudinal investigation in a national cohort of Swedish nursing students. BMC Public Health 10:343. 10.1186/1471-2458-10-343

Cohen J. 1992. A power primer. Psychol Bull 112:155-159.

Conley CS, Durlak JA, and Kirsch AC. 2015. A Meta-analysis of universal mental health prevention programs for higher education students. Prev Sci 16:487-507. 10.1007/s11121-015-0543-1

Conley CS, Durlak JA, Shapiro JB, Kirsch AC, and Zahniser E. 2016. A Meta-Analysis of the Impact of Universal and Indicated Preventive Technology-Delivered Interventions for Higher Education Students. Prev Sci 17:659-678. 10.1007/s11121-016-0662-3

Conley CS, Shapiro JB, Kirsch AC, and Durlak JA. 2017. A meta-analysis of indicated mental health prevention programs for at-risk higher education students. J Couns Psychol 64:121-140. 10.1037/cou0000190

Cvetkovski S, Reavley NJ, and Jorm AF. 2012. The prevalence and correlates of psychological distress in Australian tertiary students compared to their community peers. Aust N Z J Psychiatry 46:457467. 10.1177/0004867411435290

Dahlin M, Joneborg N, and Runeson B. 2005. Stress and depression among medical students: a crosssectional study. Med Educ 39:594-604. 10.1111/j.1365-2929.2005.02176.x

Dahlin M, Nilsson C, Stotzer E, and Runeson B. 2011. Mental distress, alcohol use and help-seeking among medical and business students: a cross-sectional comparative study. BMC Med EduC 11:92. 10.1186/1472-6920-11-92

Davies EB, Morriss R, and Glazebrook C. 2014. Computer-delivered and web-based interventions to improve depression, anxiety, and psychological well-being of university students: a systematic review and meta-analysis. J Med Internet Res 16:e130. 10.2196/jmir.3142

Dyrbye LN, Thomas MR, and Shanafelt TD. 2006. Systematic review of depression, anxiety, and other indicators of psychological distress among U.S. and Canadian medical students. Acad Med 81:354-373.

Egger M, Davey Smith G, Schneider M, and Minder C. 1997. Bias in meta-analysis detected by a simple, graphical test. BMJ 315:629 - 634 .

Eisenberg D, Hunt J, and Speer N. 2013. Mental health in American colleges and universities: variation across student subgroups and across campuses. J Nerv Ment Dis 201:60-67. 10.1097/NMD.0b013e31827ab077

Enns J, Holmqvist M, Wener P, Halas G, Rothney J, Schultz A, Goertzen L, and Katz A. 2016. Mapping interventions that promote mental health in the general population: A scoping review of reviews. Preventive Medicine 87:70-80.

Erogul M, Singer G, McIntyre T, and Stefanov DG. 2014. Abridged Mindfulness Intervention to Support Wellness in First-Year Medical Students. Teaching and Learning in Medicine 26:350-356. 10.1080/10401334.2014.945025

Farrer L, Gulliver A, Chan JK, Batterham PJ, Reynolds J, Calear A, Tait R, Bennett K, and Griffiths KM. 2013. Technology-based interventions for mental health in tertiary students: systematic review. J Med Internet Res 15:e101. 10.2196/jmir.2639 
580

581

582

583

584

585

586

587

588

589

590

591

592

593

594

595

596

597

598

599

600

601

602

603

604

605

606

607

608

609

610

611

612

613

614

615

616

617

618

619

620

621

622

623

624

625

Fontana AM, Hyra D, Godfrey L, and Cermak L. 1999. Impact of a peer-led stress inoculation training intervention on state anxiety and heart rate in college students. Journal of Applied Biobehavioral Research 4:45-63. http://dx.doi.org/10.1111/j.1751-9861.1999.tb00054.x

Franklin J, and Franklin A. 2012. The long-term independently assessed benefits of coaching: A controlled 18-month follow-up study of two methods. International Coaching Psychology Review 7:33-38.

Garlow SJ, Rosenberg J, Moore JD, Haas AP, Koestner B, Hendin H, and Nemeroff CB. 2008. Depression, desperation, and suicidal ideation in college students: results from the American Foundation for Suicide Prevention College Screening Project at Emory University. Depress Anxiety 25:482-488. 10.1002/da.20321

Gortner E-M, Rude SS, and Pennebaker JW. 2006. Benefits of Expressive Writing in Lowering Rumination and Depressive Symptoms. Behavior Therapy 37:292-303. http://dx.doi.org/10.1016/j.beth.2006.01.004

Hamdan-Mansour AM, Puskar K, and Bandak AG. 2009. Effectiveness of cognitive-behavioral therapy on depressive symptomatology, stress and coping strategies among Jordanian university students. Issues in Mental Health Nursing 30:188-196. http://dx.doi.org/10.1080/01612840802694577

Hamilton N, and Bhatti T. 1996. Population health promotion: An integrated model of population health and health promotion. In: Canada PHAo, editor. Ottawa: Health Promotion Development Division.

Hart SL, Hoyt MA, Diefenbach M, Anderson DR, Kilbourn KM, Craft LL, Steel JL, Cuijpers P, Mohr DC, and Berendsen M. 2012. Meta-analysis of efficacy of interventions for elevated depressive symptoms in adults diagnosed with cancer. Journal of the National Cancer Institute.

Higgins DM. 2006. Preventing generalized anxiety disorder in an at-risk sample of college students: A brief cognitive-behavioral approach 3235646 Ph.D. The University of Maine.

Higgins J, Thompson S, Deeks J, and Altman D. 2003. Measuring inconsistency in meta-analyses. BMJ 327:557 - 560 .

Higgins JPT, Green S, and Cochrane Collaboration. 2008. Cochrane handbook for systematic reviews of interventions. Chichester, England ; Hoboken, NJ: Wiley-Blackwell.

Hope V, and Henderson M. 2014. Medical student depression, anxiety and distress outside North America: a systematic review. Med Educ 48:963-979. 10.1111/medu.12512

Hunt J, and Eisenberg D. 2010. Mental health problems and help-seeking behavior among college students. J Adolesc Health 46:3-10. 10.1016/j.jadohealth.2009.08.008

Ibrahim AK, Kelly SJ, Adams CE, and Glazebrook C. 2013. A systematic review of studies of depression prevalence in university students. J Psychiatr Res 47:391-400. 10.1016/j.jpsychires.2012.11.015

Jane-Llopis E. 2007. Mental health promotion: concepts and strategies for reaching the population. Health Promot J Austr 18:191-197.

Jones MC, and Johnston DW. 2000. Evaluating the impact of a worksite stress management programme for distressed student nurses: A randomised controlled trial. Psychology \& Health 15:689-706. 10.1080/08870440008405480

Kanji N, White A, and Ernst E. 2006. Autogenic training to reduce anxiety in nursing students: randomized controlled trial. J Adv Nurs 53:729-735. 10.1111/j.1365-2648.2006.03779.x

Kattelmann KK, Bredbenner CB, White AA, Greene GW, Hoerr SL, Kidd T, Colby S, Horacek TM, Phillips BW, Koenings MM, Brown ON, Olfert MD, Shelnutt KP, and Morrell JS. 2014. The effects of Young Adults Eating and Active for Health (YEAH): a theory-based Web-delivered intervention. Journal of Nutrition Education \& Behavior 46:S27-41. http://dx.doi.org/10.1016/i.jneb.2014.08.007 
626

627

628

629

630

631

632

633

634

635

636

637

638

639

640

641

642

643

644

645

646

647

648

649

650

651

652

653

654

655

656

657

658

659

660

661

662

663

664

665

666

667

668

669

670

671

672

Kenardy J, McCafferty K, and Rosa V. 2006. Internet-delivered indicated prevention for anxiety disorders: Six-month follow-up. Clinical Psychologist 10:39-42. http://dx.doi.org/10.1080/13284200500378746

Keyes CL, Eisenberg D, Perry GS, Dube SR, Kroenke K, and Dhingra SS. 2012. The relationship of level of positive mental health with current mental disorders in predicting suicidal behavior and academic impairment in college students. J Am Coll Health 60:126-133. 10.1080/07448481.2011.608393

Keyes CLM. 2007. Promoting and protecting mental health as flourishing: a complementary strategy for improving national mental health. The American Psychologist 62:95-108.

Kobau R, Seligman ME, Peterson C, Diener E, Zack MM, Chapman D, and Thompson W. 2011. Mental health promotion in public health: perspectives and strategies from positive psychology. Am J Public Health 101:e1-9. 10.2105/ajph.2010.300083

Lageborn CT, Ljung R, Vaez M, and Dahlin M. 2017. Ongoing university studies and the risk of suicide: a register-based nationwide cohort study of 5 million young and middle-aged individuals in Sweden, 1993-2011. BMJ Open 7:e014264.

Leahy CM, Peterson RF, Wilson IG, Newbury JW, Tonkin AL, and Turnbull D. 2010. Distress levels and self-reported treatment rates for medicine, law, psychology and mechanical engineering tertiary students: cross-sectional study. Aust N Z J Psychiatry 44:608-615. 10.3109/00048671003649052

Li M, Fang Q, Li J, Zheng X, Tao J, Yan X, Lin Q, Lan X, Chen B, Zheng G, and Chen L. 2015. The Effect of Chinese Traditional Exercise-Baduanjin on Physical and Psychological Well-Being of College Students: A Randomized Controlled Trial. PLoS ONE [Electronic Resource] 10:e0130544. http://dx.doi.org/10.1371/journal.pone.0130544

Mak WW, Chan AT, Cheung EY, Lin CL, and Ngai KC. 2015. Enhancing Web-based mindfulness training for mental health promotion with the health action process approach: randomized controlled trial. $J$ Med Internet Res 17:e8. http://dx.doi.org/10.2196/jmir.3746

Moher D, Liberati A, Tetzlaff J, Altman DG, and Group P. 2009. Preferred reporting items for systematic reviews and meta-analyses: the PRISMA statement. PLoS Med 6:e1000097. 10.1371/journal.pmed.1000097

Pachankis JE, and Goldfried MR. 2010. Expressive writing for gay-related stress: psychosocial benefits and mechanisms underlying improvement. Journal of Consulting \& Clinical Psychology 78:98110. http://dx.doi.org/10.1037/a0017580

Peden AR, Rayens MK, Hall LA, and Beebe LH. 2001. Preventing depression in high-risk college women: a report of an 18-month follow-up. J Am Coll Health 49:299-306. 10.1080/07448480109596316

Reavley NJ, McCann TV, Cvetkovski S, and Jorm AF. 2014. A multifaceted intervention to improve mental health literacy in students of a multicampus university: a cluster randomised trial. Social Psychiatry \& Psychiatric Epidemiology 49:1655-1666. http://dx.doi.org/10.1007/s00127-014$\underline{0880-6}$

Regehr C, Glancy D, and Pitts A. 2013. Interventions to reduce stress in university students: A review and meta-analysis. Journal of Affective Disorders 148:1-11. http://dx.doi.org/10.1016/i.jad.2012.11.026

Rohde P, Stice E, Shaw H, and Gau JM. 2014. Cognitive-behavioral group depression prevention compared to bibliotherapy and brochure control: nonsignificant effects in pilot effectiveness trial with college students. Behaviour Research \& Therapy 55:48-53. http://dx.doi.org/10.1016/j.brat.2014.02.003

Rotenstein LS, Ramos MA, Torre M, Segal JB, Peluso MJ, Guille C, Sen S, and Mata DA. 2016. Prevalence of Depression, Depressive Symptoms, and Suicidal Ideation Among Medical Students: A Systematic Review and Meta-Analysis. JAMA 316:2214-2236. 10.1001/jama.2016.17324 
673

674

675

676

677

678

679

680

681

682

683

684

685

686

687

688

689

690

691

692

693

694

695

696

697

698

699

700

701

702

703

704

705

706

707

708

709

710

711

712

713

714

715

716

717

718

Rudman A, and Gustavsson JP. 2012. Burnout during nursing education predicts lower occupational preparedness and future clinical performance: a longitudinal study. Int J Nurs Stud 49:988-1001. 10.1016/j.ijnurstu.2012.03.010

Said D, Kypri K, and Bowman J. 2013. Risk factors for mental disorder among university students in Australia: findings from a web-based cross-sectional survey. Soc Psychiatry Psychiatr Epidemiol 48:935-944. 10.1007/s00127-012-0574-x

Seligman ME, Schulman P, DeRubeis RJ, and Hollon SD. 1999. The prevention of depression and anxiety. Prevention \& Treatment 2:No Pagination Specified. http://dx.doi.org/10.1037/15223736.2.1.28a

Seligman ME, Schulman P, and Tryon AM. 2007. Group prevention of depression and anxiety symptoms. Behaviour Research \& Therapy 45:1111-1126.

Shapiro SL, Brown KW, Thoresen C, and Plante TG. 2011. The moderation of Mindfulness-based stress reduction effects by trait mindfulness: results from a randomized controlled trial. Journal of Clinical Psychology 67:267-277. http://dx.doi.org/10.1002/jclp.20761

Shiralkar MT, Harris TB, Eddins-Folensbee FF, and Coverdale JH. 2013. A systematic review of stressmanagement programs for medical students. Acad Psychiatry 37:158-164. 10.1176/appi.ap.12010003

Steptoe A, Tsuda A, Tanaka Y, and Wardle J. 2007. Depressive symptoms, socio-economic background, sense of control, and cultural factors in university students from 23 countries. Int J Behav Med 14:97-107.

Tobias A. 1999. Assessing the influence of a single study in the meta-anyalysis estimate. Stata Technical Bulletin 8.

Tung YJ, Lo KKH, Ho RCM, and Tam WSW. 2018. Prevalence of depression among nursing students: A systematic review and meta-analysis. Nurse Educ Today 63:119-129. 10.1016/j.nedt.2018.01.009

Vaez M, and Laflamme L. 2008. Experienced stress, psychological symptoms, self-rated health and academic achievement: A longitudinal study of Swedish university students Social Behavior and Personality 36:183-195. 10.2224/sbp.2008.36.2.183

Wasson LT, Cusmano A, Meli L, Louh I, Falzon L, Hampsey M, Young G, Shaffer J, and Davidson KW. 2016. Association between learning environment interventions and medical student well-being: $a$ systematic review. JAMA 316:2237-2252.

Vazquez FL, Torres A, Blanco V, Diaz O, Otero P, and Hermida E. 2012. Comparison of relaxation training with a cognitive-behavioural intervention for indicated prevention of depression in university students: a randomized controlled trial. Journal of Psychiatric Research 46:1456-1463. http://dx.doi.org/10.1016/j.jpsychires.2012.08.007

Weisz JR, Sandler IN, Durlak JA, and Anton BS. 2005. Promoting and protecting youth mental health through evidence-based prevention and treatment. Am Psychol 60:628-648. 10.1037/0003$066 x .60 .6 .628$

Westerhof GJ, and Keyes CL. 2010. Mental Illness and Mental Health: The Two Continua Model Across the Lifespan. J Adult Dev 17:110-119. 10.1007/s10804-009-9082-y

Winzer R, Lindblad F, Sorjonen K, and Lindberg L. 2014. Positive versus negative mental health in emerging adulthood: a national cross-sectional survey. BMC Public Health 14:1238. 10.1186/1471-2458-14-1238

World Health Organization. 1995. Health Promoting Universities Available at http://www.who.int/healthy settings/types/universities/en/ (accessed August, 8 2016).

World Health Organization (WHO). 2002. Prevention and Promotion in Mental Health. Geneva. 
719

726
Yang W, Ding Z, Dai T, Peng F, and Zhang JX. 2014. Attention bias modification training in individuals with depressive symptoms: A randomized controlled trial. Journal of Behavior Therapy and Experimental Psychiatry:No Pagination Specified. http://dx.doi.org/10.1016/i.jbtep.2014.08.005

Zheng G, Lan X, Li M, Ling K, Lin H, Chen L, Tao J, Li J, Zheng X, Chen B, and Fang Q. 2015. Effectiveness of Tai Chi on Physical and Psychological Health of College Students: Results of a Randomized Controlled Trial. PLoS ONE [Electronic Resource] 10:e0132605. http://dx.doi.org/10.1371/journal.pone.0132605 


\section{Table $\mathbf{1}$ (on next page)}

Summary of study characteristics of randomized controlled trials included in the systematic review and meta-analysis.

${ }^{a}$ E.g. a different variant of the same intervention, a different intervention.

'E.g. no intervention, "living as usual", a waiting list control

c Percentage does not add to 100 because studies could fall into multiple categories.

${ }^{d}$ Assessed by The Effective Public Health Practice Project Quality Assessment Tool (EPHPP). 
1 Table 1 Summary of descriptive characteristics of randomized controlled 2 trials included in systematic review and meta-analysis

3

\begin{tabular}{|c|c|c|}
\hline & $\begin{array}{c}\text { Number of } \\
\text { comparisons }(k)\end{array}$ & $\%$ \\
\hline Total number of studies & 26 & 100 \\
\hline \multicolumn{3}{|l|}{ Participant characteristics } \\
\hline \multicolumn{3}{|l|}{ Gender mix, Study population } \\
\hline Approx. even $(40-60$ females $)$ & 6 & 23.0 \\
\hline More than $60 \%$ females & 17 & 65.0 \\
\hline More than $60 \%$ males & 1 & 4.0 \\
\hline Not reported & 2 & 8.0 \\
\hline \multicolumn{3}{|l|}{ Region (countries) } \\
\hline US & 14 & 54.0 \\
\hline Australia & 3 & 11.5 \\
\hline Europe (UK, Scotland, Spain) & 3 & 11.5 \\
\hline East Asia and Pacific (China + Hong Kong) & 5 & 19.0 \\
\hline Middle East and North Africa (Jordan) & 1 & 4.0 \\
\hline \multicolumn{3}{|l|}{ Intervention characteristics } \\
\hline \multicolumn{3}{|l|}{ Intervention classification } \\
\hline CBT-related & 11 & 42.0 \\
\hline Mind-body-related & 10 & 39.0 \\
\hline Psycho-educational-related & 5 & 19.0 \\
\hline \multicolumn{3}{|l|}{ Enlarged with Material/Home-work/Training/Booster } \\
\hline Yes & 15 & 58.0 \\
\hline No/Unclear & 11 & 42.0 \\
\hline \multicolumn{3}{|l|}{ Type of delivery } \\
\hline Universal & 13 & 50.0 \\
\hline Selective & 13 & 50.0 \\
\hline \multicolumn{3}{|l|}{ Type of format } \\
\hline Internet-based individual & 5 & 19.0 \\
\hline Internet-based individual and in groups & 2 & 8.0 \\
\hline Face-to-face individual & 2 & 8.0 \\
\hline Face-to- face in group & 16 & 61.0 \\
\hline Face-to-face in pairs & 1 & 4.0 \\
\hline \multicolumn{3}{|l|}{ Length of intervention } \\
\hline$<1$ week & 4 & 15.0 \\
\hline $1-4$ weeks & 1 & 4.0 \\
\hline $5-7$ weeks & 7 & 27.0 \\
\hline 8 weeks & 8 & 31.0 \\
\hline 9-12 weeks & 5 & 19.0 \\
\hline 13-16 weeks & 0 & 0.0 \\
\hline$>16$ weeks & 1 & 4.0 \\
\hline \multicolumn{3}{|l|}{ Comparison condition } \\
\hline Active control ${ }^{\mathrm{a}}$ & 8 & 31.0 \\
\hline Inactive control $^{\mathrm{b}}$ & 18 & 69.0 \\
\hline \multicolumn{3}{|l|}{ Study characteristics } \\
\hline \multicolumn{3}{|l|}{ Length of follow-up ${ }^{c}$} \\
\hline 3 months & 13 & 50.0 \\
\hline 4-6 months & 14 & 54.0 \\
\hline
\end{tabular}




\begin{tabular}{|ccc}
\hline $7-9$ months & 3 & 11.5 \\
$10-12$ months & 7 & 27.0 \\
$13-15$ months & 0 & 0.0 \\
$>15$ months & 5 & 19.0 \\
Study size (participants) & & \\
$\mathrm{n} \leq 100$ & 16 & 62.0 \\
$\mathrm{n}>100$ & 10 & 38.0 \\
Study quality $\mathrm{d}$ & & \\
Weak & 10 & 39.0 \\
Moderate & 12 & 46.0 \\
Strong & 4 & 15.0 \\
\hline
\end{tabular}

4

$5 \quad{ }^{a}$ E.g. a different variant of the same intervention, a different intervention.

6 b E.g. no intervention, "living as usual", a waiting list control

$7 \quad{ }^{\mathrm{c}}$ Percentage does not add to 100 because studies could fall into multiple categories.

8 d Assessed by The Effective Public Health Practice Project Quality Assessment Tool (EPHPP). 


\section{Table 2 (on next page)}

Meta-analysis and sub-group analyses for hierarchically selected mental ill health outcomes, stratified by the length of post interventional follow-up periods.

k; number of studies; n/a; not applicable

$(*) p<0.1 * p<0.05, * * p<0.01, * * * p<0.001$

The format type "face-to-face in pair" was not utilized for mental ill health outcomes. [p] 
1 Table 2 Meta-analysis and sub-group analyses for hierarchically selected mental ill health outcomes, 2 stratified by the length of post interventional follow-up periods.

3

4

\begin{tabular}{|c|c|c|c|}
\hline \multirow[t]{2}{*}{ Variables } & \multicolumn{3}{|c|}{ Length of post intervention follow-up periods (months) } \\
\hline & 3-6 & $7-12$ & 13-18 \\
\hline All interventions (k) & 21 & 9 & 3 \\
\hline Hedges’ g (95\% CI) & $-0.28(-0.44,-0.12)$ & $-0.28(-0.49,-0.08)$ & $-0.17(-0.39,0.05)$ \\
\hline $\mathrm{Q} / \mathrm{I}^{2}$ & $97.50 * * * / 79.5 \%$ & $31.00 * * * / 74.2 \%$ & $4.78(*) / 58.2 \%$ \\
\hline \multicolumn{4}{|l|}{ Subgroup analyses } \\
\hline \multicolumn{4}{|l|}{ Type of interventions } \\
\hline CBT-related (k) & 11 & 4 & 2 \\
\hline Hedges'g $(95 \%$ CI $)$ & $-0.40(-0.64,-0.16)$ & $-0.12(-0.51,0.16)$ & $-0.30(-0.51,-0.08)$ \\
\hline $\mathrm{Q} / \mathrm{I}^{2}$ & $44.60 * * * / 77.6 \%$ & $7.61(*) / 60.6 \%$ & $0.28 / 0.0 \%$ \\
\hline Mind-body related $(\mathrm{k})$ & 9 & 3 & 0 \\
\hline Hedges' g $(95 \%$ CI) & $-0.20(-0.44,0.04)$ & $-0.43(-0.66,-0.20)$ & --- \\
\hline $\mathrm{Q} / \mathrm{I}^{2}$ & $33.30 * * * / 76.0 \%$ & $1.00 / 0.0 \%$ & --- \\
\hline Psychoeducational (k) & 1 & 2 & 1 \\
\hline Hedges’ g (95\% CI) & $0.09(-0.05,0.23)$ & $-0.64(-1.83,0.54)$ & $-0.02(-0.16,0.16)$ \\
\hline $\mathrm{Q} / \mathrm{I}^{2}$ & --- - & $16.58 * * * / 94.0 \%$ & --- \\
\hline Group difference $\mathrm{Q}(\mathrm{df}) / \mathrm{p}$ for $\mathrm{Q}$ & $3.38(1) / 0.06$ & $5.82(2) / 0.05$ & $\mathrm{n} / \mathrm{a}$ \\
\hline \multicolumn{4}{|l|}{ Delivery level } \\
\hline Universal (k) & 8 & 5 & 1 \\
\hline Hedges'g $(95 \%$ CI $)$ & $-0.23(-0.46,-0.01)$ & $-0.46(-0.83,-0.09)$ & $-0.02(-0.16,0.12)$ \\
\hline $\mathrm{Q} / \mathrm{I}^{2}$ & $34.23 * * * / 79.6 \%$ & $23.04 * * * / 82.6 \%$ & --- \\
\hline Selective $(k)$ & 13 & 4 & 2 \\
\hline Hedges' g $(95 \% \mathrm{CI})$ & $-0.31(-0.54,-0.08)$ & $-0.12(-0.39,0.16)$ & $-0.30(-0.51,-0.08)$ \\
\hline $\mathrm{Q} / \mathrm{I}^{2}$ & $55.74 * * * / 78.5 \%$ & $7.61(*) / 60.6 \%$ & $0.28 / 0.0 \%$ \\
\hline Group difference Q (df) / p for Q & $7.48(1) / 0.006$ & $0.35(1) / 0.55$ & $\mathrm{n} / \mathrm{a}$ \\
\hline \multicolumn{4}{|l|}{ Format type } \\
\hline Face-to-face in group $(\mathrm{k})$ & 15 & 6 & 2 \\
\hline Hedges' g $(95 \% \mathrm{CI})$ & $-0.35(-0.54,-0.16)$ & $-0.20(-0.42,0.03)$ & $-0.30(-0.51,-0.08)$ \\
\hline $\mathrm{Q} / \mathrm{I}^{2}$ & $55.20 * * * / 74.6 \%$ & $11.68 * / 57.2 \%$ & $0.28 / 0.0 \%$ \\
\hline Face-to-face individual (k) & 2 & 0 & 0 \\
\hline Hedges' g $(95 \% \mathrm{CI})$ & $0.06(-0.30,0.42)$ & --- & --- \\
\hline $\mathrm{Q} / \mathrm{I}^{2}$ & $1.91 / 47.5 \%$ & --- & --- \\
\hline Internet-based individual (k) & 2 & 2 & 0 \\
\hline Hedges' g $(95 \% \mathrm{CI})$ & $-0.28(-1.09,0.53)$ & $-0.64(-1.83,0.54)$ & --- \\
\hline $\mathrm{Q} / \mathrm{I}^{2}$ & $6.26 * / 84.0 \%$ & $16.58 * * * / 94.0 \%$ & --- \\
\hline Internet-based individual and in groups (k) & 2 & 1 & 1 \\
\hline Hedges' g $(95 \% \mathrm{CI})$ & $-0.30(-1.10,0.50)$ & $-0.45(-0.84,-0.07)$ & $-0.02(-0.16,0.12)$ \\
\hline $\mathrm{Q} / \mathrm{I}^{2}$ & $15.17 * * * / 93.4 \%$ & --- - - & --- - (- \\
\hline Group difference $\mathrm{Q}(\mathrm{df}) / \mathrm{p}$ for $\mathrm{Q}$ & $\mathrm{n} / \mathrm{a}$ & $0.56(1) / 0.45$ & $\mathrm{n} / \mathrm{a}$ \\
\hline \multicolumn{4}{|l|}{ Type of comparison } \\
\hline Active $(\mathrm{k})$ & 2 & 2 & 0 \\
\hline Hedges' g (95\% CI) & $-0.34(-1.21,0.53)$ & $-0.88(-1.59,-0.18)$ & --- \\
\hline $\mathrm{Q} / \mathrm{I}^{2}$ & $12.40 * * * / 91.9 \%$ & $4.45 * / 77.5 \%$ & --- \\
\hline Inactive (k) & 19 & 7 & 3 \\
\hline Hedges' g $(95 \% \mathrm{CI})$ & $-0.28(-0.44,-0.11)$ & $-0.14(-0.28,0.01)$ & $-0.17(-0.39,0.05)$ \\
\hline $\mathrm{Q} / \mathrm{I}^{2}$ & $83.38 * * * / 78.4 \%$ & $10.17 / 41.0 \%$ & $4.78 / 58.2 \%$ \\
\hline Group difference $\mathrm{Q}(\mathrm{df}) / \mathrm{p}$ for $\mathrm{Q}$ & $1.67(1) / 0.20$ & $16.39(1) /<0.001$ & $\mathrm{n} / \mathrm{a}$ \\
\hline \multicolumn{4}{|l|}{ Study quality } \\
\hline Strong $(\mathrm{k})$ & 2 & 2 & 1 \\
\hline Hedges' g $(95 \%$ CI) & $-0.22(-0.63,0.19)$ & $-0.17(-0.34,0.01)$ & $-0.26(-0.52,-0.01)$ \\
\hline $\mathrm{Q} / \mathrm{I}^{2}$ & $2.50 / 60.0 \%$ & $0.06 / 0.0 \%$ & -- \\
\hline
\end{tabular}




\begin{tabular}{|c|c|c|c|}
\hline Moderate $(\mathrm{k})$ & 10 & 4 & 0 \\
\hline Hedges' g $(95 \%$ CI $)$ & $-0.26(-0.44,-0.09)$ & $-0.38(-0.99,0.24)$ & --- \\
\hline $\mathrm{Q} / \mathrm{I}^{2}$ & $21.12 * / 57.4 \%$ & $21.82 * * * / 86.2 \%$ & --- \\
\hline Weak (k) & 9 & 3 & 2 \\
\hline Hedges' g $(95 \% \mathrm{CI})$ & $-0.30(-0.62,0.02)$ & $-0.23(-0.61,0.02)$ & $-0.15(-0.50,0.20)$ \\
\hline $\mathrm{Q} / \mathrm{I}^{2}$ & $71.20 * * * / 88.8 \%$ & $8.29 * / 75.9 \%$ & $2.82 / 64.6 \%$ \\
\hline Group difference $\mathrm{Q}(\mathrm{df}) / \mathrm{p}$ for $\mathrm{Q}$ & $2.63(2) / 0.27$ & $0.85(2) / 0.65$ & $\mathrm{n} / \mathrm{a}$ \\
\hline \multicolumn{4}{|l|}{ Study size } \\
\hline 100 participants or less $(\mathrm{k})$ & 14 & 7 & 1 \\
\hline Hedges' $\mathrm{g}(95 \% \mathrm{CI})$ & $-0.45(-0.68,-0.23)$ & $-0.38(-0.71,-0.05)$ & $-0.39(-0.80,0.02)$ \\
\hline $\mathrm{Q} / \mathrm{I}^{2}$ & $44.08 * * * / 70.5 \%$ & $23.91 * * / 74.9 \%$ & --- - (2) \\
\hline More than 100 participants $(\mathrm{k})$ & 7 & 2 & 2 \\
\hline Hedges’g $(95 \%$ CI) & $-0.01(-0.10,0.08)$ & $-0.09(-0.20,0.00)$ & $-0.12(-0.34,0.12)$ \\
\hline $\mathrm{Q} / \mathrm{I}^{2}$ & $7.07 / 15.1 \%$ & $0.69 / 0.0 \%$ & $2.66 / 62.4 \%$ \\
\hline Group difference $\mathrm{Q}(\mathrm{df}) / \mathrm{p}$ for $\mathrm{Q}$ & $46.3(1) /<0.001$ & $6.41(1) / 0.01$ & $\mathrm{n} / \mathrm{a}$ \\
\hline \multicolumn{4}{|l|}{ Participants' gender mix } \\
\hline Approx. even $(40 \%-60 \%$ females $)(\mathrm{k})$ & 3 & 1 & 1 \\
\hline Hedges' g $(95 \%$ CI $)$ & $-0.31(-0.65,0.04)$ & $-0.16(-0.34,0.02)$ & $-0.26(-0.52,-0.01)$ \\
\hline $\mathrm{Q} / \mathrm{I}^{2}$ & $5.40 / 63.0 \%$ & --- & --- \\
\hline More than $60 \%$ females $(\mathrm{k})$ & 14 & 8 & 2 \\
\hline Hedges' g $(95 \% \mathrm{CI})$ & $-0.32(-0.52,-0.11)$ & $-0.32(-0.58,-0.06)$ & $-0.15(-0.50,0.20)$ \\
\hline $\mathrm{Q} / \mathrm{I}^{2}$ & $80.27 * * * / 83.3 \%$ & $31.0 * * * / 77.4 \%$ & $2.82 / 64.6 \%$ \\
\hline More than $60 \%$ males $(\mathrm{k})$ & 1 & 0 & 0 \\
\hline Hedges' g $(95 \% \mathrm{CI})$ & $0.30(-0.17,0.77)$ & --- & --- \\
\hline $\mathrm{Q} / \mathrm{I}^{2}$ & --- & --- & --- \\
\hline Not reported (k) & 3 & 0 & 0 \\
\hline Hedges' g $(95 \%$ CI $)$ & $-0.25(-0.94,0.44)$ & --- & --- \\
\hline $\mathrm{Q} / \mathrm{I}^{2}$ & $7.73 * / 74.1 \%$ & --- & --- \\
\hline Group difference $\mathrm{Q}(\mathrm{df}) / \mathrm{p}$ for $\mathrm{Q}$ & $0.45(2) / 0.80$ & $\mathrm{n} / \mathrm{a}$ & $\mathrm{n} / \mathrm{a}$ \\
\hline \multicolumn{4}{|l|}{ Country } \\
\hline US (k) & 10 & 6 & 2 \\
\hline Hedges' g $(95 \% \mathrm{CI})$ & $-0.22(-0.47,0.03)$ & $-0.20(-0.45,0.06)$ & $-0.30(-0.51,-0.08)$ \\
\hline $\mathrm{Q} / \mathrm{I}^{2}$ & $35.73 * * * / 74.8 \%$ & $21.48 * * / 76.7 \%$ & $0.28 / 0.0 \%$ \\
\hline Other countries $(\mathrm{k})$ & 11 & 3 & 1 \\
\hline Hedges' g $(95 \%$ CI $)$ & $-0.33(-0.55,-0.11)$ & $-0.45(-0.66,-0.25)$ & $-0.02(-0.16,0.12)$ \\
\hline $\mathrm{Q} / \mathrm{I}^{2}$ & $60.57 * * * / 83.5 \%$ & $0.71 / 0.0 \%$ & --- - - \\
\hline Group difference $\mathrm{Q}(\mathrm{df}) / \mathrm{p}$ for $\mathrm{Q}$ & $1.15(1) / 0.28$ & $8.82(1) / 0.003$ & $\mathrm{n} / \mathrm{a}$ \\
\hline
\end{tabular}

$\mathrm{k}$; number of studies; $\mathrm{n} / \mathrm{a}$; not applicable

$\left({ }^{*}\right) \mathrm{p}<0.1 * \mathrm{p}<0.05,{ }^{* *} \mathrm{p}<0.01,{ }^{* * *} \mathrm{p}<0.001$

The format type "face-to-face in pair" was not utilized for mental ill health outcomes. 


\section{Table 3(on next page)}

Meta-analysis and sub-group analyses for hierarchically selected positive mental health and academic performance outcomes stratified by the length of post interventional follow-up periods.

$\mathrm{k}$; number of studies; n/a; not applicable $(*) p<0.1 * p<0.05,{ }^{* *} p<0.01,{ }^{* * *} p<0.001$. The format type "Internet-based individual and in groups" was not utilized for positive mental health and academic performance outcomes. 
1 Table 3 Meta-analysis and sub-group analyses for hierarchically selected positive mental health and 2 academic performance outcomes stratified by the length of post interventional follow-up periods.

\begin{tabular}{|c|c|c|c|}
\hline \multirow[t]{2}{*}{ Variables } & \multicolumn{3}{|c|}{ Length of post intervention follow-up periods (months) } \\
\hline & 3-6 & $7-12$ & 13-18 \\
\hline All interventions (k) & 11 & 2 & 2 \\
\hline Hedges' g $(95 \%$ CI $)$ & $0.32(0.05,0.59)$ & $0.34(-0.05,0.73)$ & $0.33(-0.06,0.72)$ \\
\hline $\mathrm{Q} / \mathrm{I}^{2}$ & $73.8 * * * / 86.5 \%$ & $0.00 / 0.0 \%$ & $0.04 / 0.0 \%$ \\
\hline \multicolumn{4}{|l|}{ Subgroup analyses } \\
\hline \multicolumn{4}{|l|}{ Type of interventions } \\
\hline CBT-related (k) & 4 & 0 & 1 \\
\hline Hedges' g $(95 \%$ CI $)$ & $0.52(0.06,0.98)$ & --- & $0.29(-0.29,0.87)$ \\
\hline $\mathrm{Q} / \mathrm{I}^{2}$ & $24.5 * * * / 87.8 \%$ & --- & --- \\
\hline Mind-body related $(\mathrm{k})$ & 6 & 1 & 0 \\
\hline Hedges’ g $(95 \%$ CI $)$ & $0.23(-0.16,0.61)$ & $0.35(-0.35,1.05)$ & --- \\
\hline $\mathrm{Q} / \mathrm{I}^{2}$ & $41.68 * * * / 88.0 \%$ & --- & --- \\
\hline Psychoeducational (k) & 1 & 1 & 1 \\
\hline Hedges’ g (95\% CI) & $0.10(-0.38,0.58)$ & $0.34(-0.14,0.82)$ & $0.37(-0.17,0.91)$ \\
\hline $\mathrm{Q} / \mathrm{I}^{2}$ & --- & --- & --- \\
\hline Group difference $\mathrm{Q}(\mathrm{df}) / \mathrm{p}$ for $\mathrm{Q}$ & & $\mathrm{n} / \mathrm{a}$ & $\mathrm{n} / \mathrm{a}$ \\
\hline \multicolumn{4}{|l|}{ Delivery level } \\
\hline Universal (k) & 5 & 2 & 1 \\
\hline Hedges' g $(95 \%$ CI $)$ & $0.05(-0.23,0.33)$ & $0.34(-0.05,0.74)$ & $0.37(-0.17,0.91)$ \\
\hline $\mathrm{Q} / \mathrm{I}^{2}$ & $21.75 * * / 77.0 \%$ & $0.00 / 0.0 \%$ & --- \\
\hline Selective (k) & 5 & 0 & 1 \\
\hline Hedges' g $(95 \%$ CI $)$ & $0.64(0.18,1.09)$ & --- & $0.29(-0.29,0.87)$ \\
\hline $\mathrm{Q} / \mathrm{I}^{2}$ & $34.8 * * * / 88.5 \%$ & --- & --- \\
\hline Group difference $\mathrm{Q}(\mathrm{df}) / \mathrm{p}$ for $\mathrm{Q}$ & $17.26(1) /<0.001$ & $\mathrm{n} / \mathrm{a}$ & $\mathrm{n} / \mathrm{a}$ \\
\hline \multicolumn{4}{|l|}{ Format type } \\
\hline Face-to-face in groups (k) & 6 & 1 & 1 \\
\hline Hedges' g $(95 \% \mathrm{CI})$ & $0.53(0.16,0.91)$ & $0.35(-0.35,1.05)$ & $0.29(-0.29,0.87)$ \\
\hline $\mathrm{Q} / \mathrm{I}^{2}$ & $27.34 * * * / 81.7 \%$ & --- & --- \\
\hline \multicolumn{4}{|l|}{ Face-to-face individual (k) } \\
\hline $\mathrm{k}$ & 2 & 0 & 0 \\
\hline Hedges' g $(95 \%$ CI $)$ & $0.51(-0.63,1.66)$ & --- & --- \\
\hline $\mathrm{Q} / \mathrm{I}^{2}$ & $16.17 * * * / 93.8 \%$ & --- & --- \\
\hline Face-to-face in pairs (k) & 0 & 1 & 1 \\
\hline Hedges’ g $(95 \%$ CI $)$ & --- & $0.34(-0.14,0.82)$ & $0.37(-0.17,0.91)$ \\
\hline $\mathrm{Q} / \mathrm{I}^{2}$ & --- & 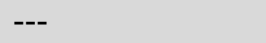 & --- \\
\hline Internet-based individual (k) & 3 & 0 & 0 \\
\hline Hedge’s g $(95 \%$ CI $)$ & $-0.14(-0.36,0.07)$ & --- & --- \\
\hline $\mathrm{Q} / \mathrm{I}^{2}$ & $4.42 / 54.8 \%$ & --- & --- \\
\hline Group difference $\mathrm{Q}(\mathrm{df}) / \mathrm{p}$ for $\mathrm{Q}$ & $25.88(2) /<0.001$ & $\mathrm{n} / \mathrm{a}$ & $\mathrm{n} / \mathrm{a}$ \\
\hline \multicolumn{4}{|l|}{ Type of comparison } \\
\hline Active $(\mathrm{k})$ & 1 & 0 & 0 \\
\hline Hedges' g $(95 \% \mathrm{CI})$ & $-0.11(-0.50,0.28)$ & --- & --- \\
\hline $\mathrm{Q} / \mathrm{I}^{2}$ & --- & --- & --- \\
\hline Inactive (k) & 10 & 2 & 2 \\
\hline Hedges' g $(95 \% \mathrm{CI})$ & $0.36(0.08,0.65)$ & $0.34(-0.05,0.74)$ & $0.33(-0.06,0.73)$ \\
\hline $\mathrm{Q} / \mathrm{I}^{2}$ & $72.53 * * * / 87.6 \%$ & $0.00 / 0.0 \%$ & $0.04 / 0.0 \%$ \\
\hline Group difference $\mathrm{Q}(\mathrm{df}) / \mathrm{p}$ for $\mathrm{Q}$ & $\mathrm{n} / \mathrm{a}$ & $\mathrm{n} / \mathrm{a}$ & $\mathrm{n} / \mathrm{a}$ \\
\hline \multicolumn{4}{|l|}{ Study quality } \\
\hline Strong $(\mathrm{k})$ & 2 & 1 & 0 \\
\hline
\end{tabular}




\begin{tabular}{|c|c|c|c|}
\hline Hedges' g $(95 \%$ CI $)$ & $0.49(-0.53,1.51)$ & $0.35(-0.35,1.05)$ & --- \\
\hline $\mathrm{Q} / \mathrm{I}^{2}$ & $12.33 * * * / 91.9 \%$ & --- & --- \\
\hline Moderate $(\mathrm{k})$ & 5 & 0 & 0 \\
\hline Hedges' g $(95 \% \mathrm{CI})$ & $0.18(-0.11,0.47)$ & --- & --- \\
\hline $\mathrm{Q} / \mathrm{I}^{2}$ & $17.02 * * / 76.5 \%$ & --- & --- \\
\hline Weak (k) & 4 & 1 & 2 \\
\hline Hedges' g $(95 \%$ CI) & $0.48(-0.30,1.25)$ & $0.34(-0.14,0.82)$ & $0.33(-0.06,0.73)$ \\
\hline $\mathrm{Q} / \mathrm{I}^{2}$ & $43.94 * * * / 93.2 \%$ & --- & $0.04 / 0.0 \%$ \\
\hline Group difference $\mathrm{Q}(\mathrm{df}) / \mathrm{p}$ for $\mathrm{Q}$ & $0.53(2) / 0.77$ & $\mathrm{n} / \mathrm{a}$ & $\mathrm{n} / \mathrm{a}$ \\
\hline \multicolumn{4}{|l|}{ Study size } \\
\hline 100 participants or less $(\mathrm{k})$ & 5 & 1 & 1 \\
\hline Hedges'g $(95 \% \mathrm{CI})$ & $0.84(0.46,1.23)$ & $0.35(-0.35,1.05)$ & $0.29(-0.29,0.87)$ \\
\hline $\mathrm{Q} / \mathrm{I}^{2}$ & $11.97 * / 66.6 \%$ & --- & --- \\
\hline More than 100 participants $(\mathrm{k})$ & 6 & 1 & 1 \\
\hline Hedges' g $(95 \% \mathrm{CI})$ & $-0.04(-0.20,0.13)$ & $0.34(-0.14,0.82)$ & $0.37(-0.017,0.91)$ \\
\hline $\mathrm{Q} / \mathrm{I}^{2}$ & $12.01 * / 58.4 \%$ & --- & --- \\
\hline Group difference $\mathrm{Q}(\mathrm{df}) / \mathrm{p}$ for $\mathrm{Q}$ & $49.84(1) /<0.001$ & $\mathrm{n} / \mathrm{a}$ & $\mathrm{n} / \mathrm{a}$ \\
\hline \multicolumn{4}{|l|}{ Participants' gender mix } \\
\hline Approx. even $(40 \%-60 \%$ females $)(\mathrm{k})$ & 4 & 1 & 1 \\
\hline Hedges' g $(95 \% \mathrm{CI})$ & $0.49(-0.06,1.03)$ & $0.34(-0.14,0.82)$ & $0.37(-0.017,0.91)$ \\
\hline $\mathrm{Q} / \mathrm{I}^{2}$ & $22.88 * * * / 86.9 \%$ & -- & -- \\
\hline More than $60 \%$ females $(\mathrm{k})$ & 6 & 1 & 1 \\
\hline Hedge's g $(95 \% \mathrm{CI})$ & $0.10(-0.19,0.40)$ & $0.35(-0.35,1.05)$ & $0.29(-0.29,0.87)$ \\
\hline $\mathrm{Q} / \mathrm{I}^{2}$ & $29.73 * * * / 83.2 \%$ & --- & --- - \\
\hline More than $60 \%$ males $(\mathrm{k})$ & 1 & 0 & 0 \\
\hline Hedges' g $(95 \% \mathrm{CI})$ & $1.12(0.62,1.63)$ & --- & --- \\
\hline $\mathrm{Q} / \mathrm{I}^{2}$ & --- - - & --- & --- \\
\hline Not reported (k) & 0 & 0 & 0 \\
\hline Hedges'g $(95 \%$ CI $)$ & --- & --- & --- \\
\hline $\mathrm{Q} / \mathrm{I}^{2}$ & --- & --- & --- \\
\hline Group difference $\mathrm{Q}(\mathrm{df}) / \mathrm{p}$ for $\mathrm{Q}$ & $5.18(1) / 0.02$ & $\mathrm{n} / \mathrm{a}$ & $\mathrm{n} / \mathrm{a}$ \\
\hline \multicolumn{4}{|l|}{ Country } \\
\hline US $(\mathrm{k})$ & 6 & 1 & 1 \\
\hline Hedges' g $(95 \% \mathrm{CI})$ & $0.52(0.11,0.93)$ & $0.35(-0.35,1.05)$ & $0.29(-0.29,0.87)$ \\
\hline $\mathrm{Q} / \mathrm{I}^{2}$ & $38.79 * * * / 87.1 \%$ & --- & --- - \\
\hline Other countries $(\mathrm{k})$ & 5 & 1 & 1 \\
\hline Hedges' g $(95 \% \mathrm{CI})$ & $0.09(-0.25,0.44)$ & $0.34(-0.14,0.82)$ & $0.37(-0.017,0.91)$ \\
\hline $\mathrm{Q} / \mathrm{I}^{2}$ & $24.24 * * * / 83.5 \%$ & --- & --- - (2) \\
\hline Group difference $\mathrm{Q}(\mathrm{df}) / \mathrm{p}$ for $\mathrm{Q}$ & $10.78(1) / 0.001$ & $\mathrm{n} / \mathrm{a}$ & $\mathrm{n} / \mathrm{a}$ \\
\hline
\end{tabular}

$\mathrm{k}$; number of studies; $\mathrm{n} / \mathrm{a}$; not applicable

$(*) \mathrm{p}<0.1 * \mathrm{p}<0.05, * * \mathrm{p}<0.01, * * * \mathrm{p}<0.001$

The format type "Internet-based individual and in groups" was not utilized for positive mental health and academic performance outcomes. 


\section{Figure 1 (on next page)}

Flow diagram of the study selection process.

PRISMA flow diagram From: Moher D, Liberati A, Tetzlaff J, Altman DG, P referred Reporting Items for Systematic Reviews and Meta-Analyses: The PRISMA Statement. PLoS Med 6(6): e1000097. doi:10.1371/journal.pmed1000097 
Records identified through database searching $(n=6004)$

Medline (Ovid) ( $n=961$ )

Psyclnfo (Ovid) $(n=2462)$

Eric (Ovid) $(n=420)$

Scopus $(n=2161)$
Records identified through other sources: Reference lists of included studies, relevant Journals $(n=27)$

Records after duplicates removed $(n=5016)$

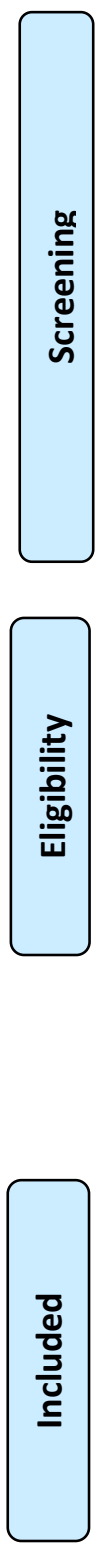

\section{Search update for Medline, Psyclnfo, Eric, Scopus $(n=352)$}

Gray literature searches Dart Europe $(n=310)$ Open Grey $(n=250)$

Base Bielefeld ( $n=144)$

Dissertations \& Theses ( $n=499$ )

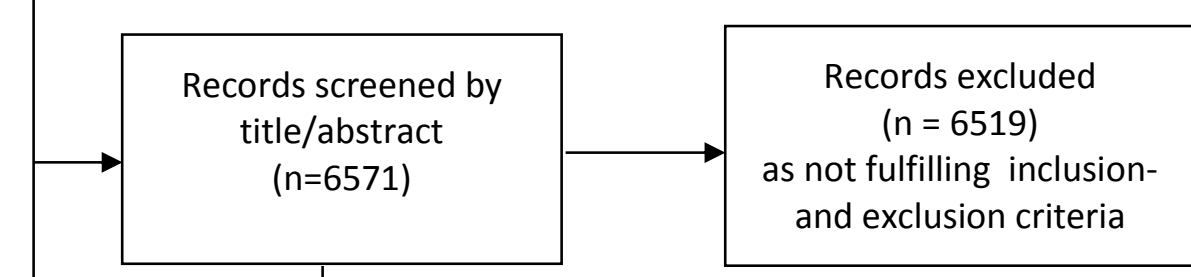

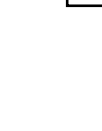

Full-text articles excluded $(n=$ 26)

Reasons:

Post-intervention follow-up $<3$ months $(n=11)$

Not enough data to calculate ES $(n=6)$

Not RCT $(n=5)$

Not relevant population $(n=3)$

Not relevant outcome $(n=1)$ 
Figure 2

The effects of mental ill health preventing interventions on hierarchically selected mental ill health outcomes stratified by the length of post interventional follow-up periods.

Lines represent standardized difference in means (Hedges'g) and 95\% confidence intervals $(\mathrm{Cl})$; the size of the box represents the weight of each study.

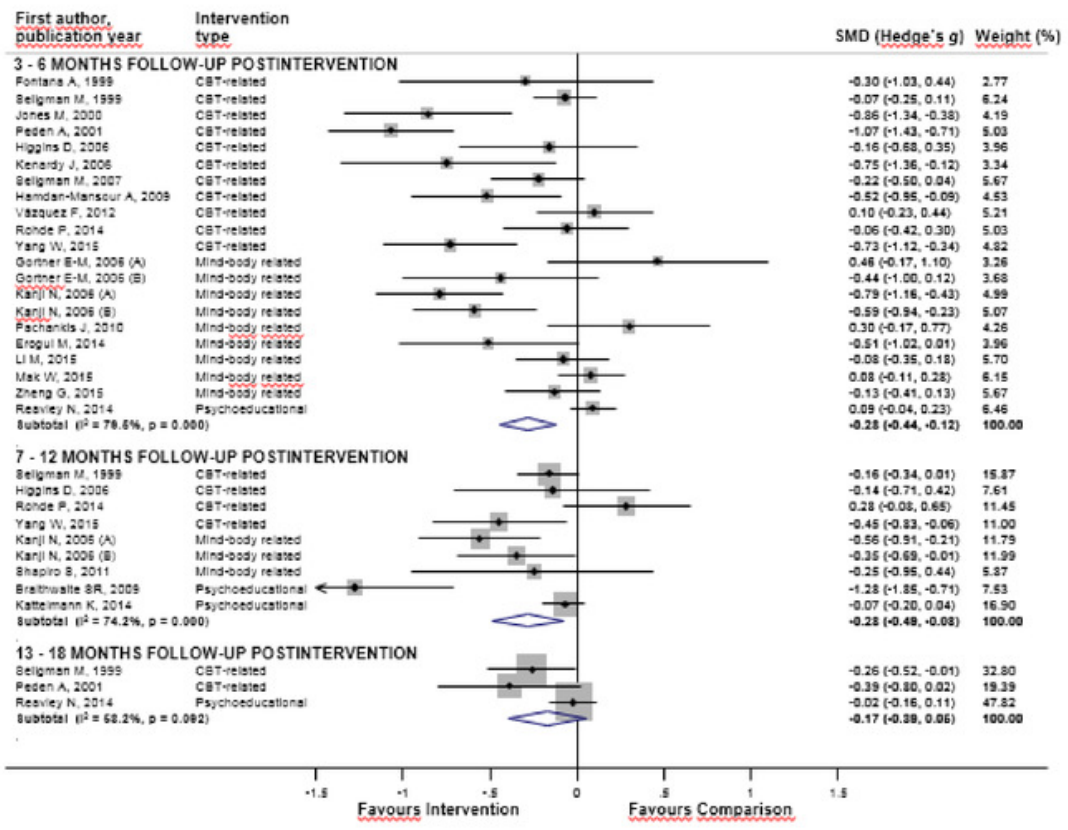




\section{Figure 3}

Theeffects of mental health promoting interventions on hierarchically selectedpositive mental health and academic performance outcomes stratified by thelength of post interventional follow-up periods.

The effect sizes of all interventions and combined subtotals for positive mental health and academic performance outcomes by the length of follow-up. Lines represent standardized difference in means (Hedges' $\mathrm{g}$ ) and 95\% confidence intervals $(\mathrm{Cl})$; the size of the box represents the weight of each study. 


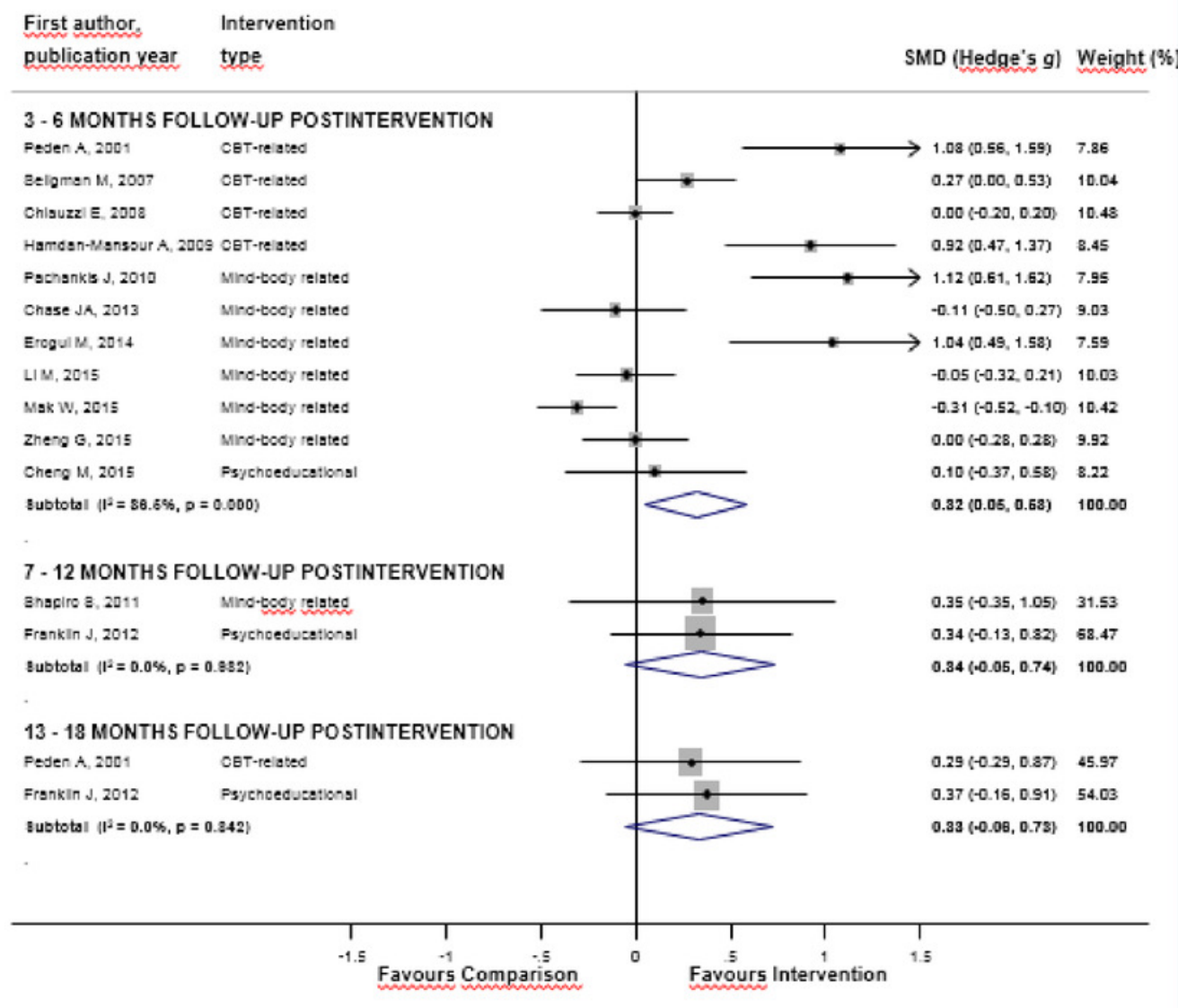

